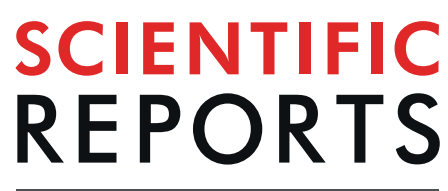

natureresearch

Check for updates

\title{
Quantification of adsorbed and dangling citrate ions on gold nanoparticle surface using thermogravimetric analysis
}

\begin{abstract}
Manish Bajaj ${ }^{1}$, Nishima Wangoo², D. V. S. Jain ${ }^{1,3}$ \& Rohit K. Sharma $\mathbb{D}^{1 凶}$
A novel approach involving thermo-gravimetricanalysis (TGA) for the quantification of citrate ions present on the surface of gold nanoparticles has been reported. TGA study was carried out on AuNPs in response to parameters such as concentration of tri-sodium citrate and $\mathrm{pH}$ of gold nanoparticles depicting that the number of citrate ion present on gold nanoparticles is highly pH dependent. In general, the citrate ions were observed to be higher in alkaline conditions contradicting earlier beliefs. These results also underline the significance of TGA as a novel tool for quantification of citrate molecules present on gold nanoparticle surface. Thus, the present approach not only provides with an insight into mechanistic details of gold nanoparticle synthesis but also opens the usage of TGA for understanding the nano range association of molecules.
\end{abstract}

Gold nanoparticles (AuNPs) have gained considerable popularity as one of the most stable metal nanoparticles with unique electrical, optical and surface chemical properties making them applicable in fields such as sensing, drug delivery, cancer therapy and tissue engineering ${ }^{1-4}$. It is well known that AuNPs can be synthesized using different chemical reduction methods; out of which the citrate method introduced by Turkevich is the most widely used for the preparation of AuNPs ${ }^{5,6}$ The biocompatible nature of citrate ion and its ability to act as a cross-linker between various ligands along with its labile nature with respect to displacement by various ligands on the surface of AuNPs render Turkevich method as one of the most popular for AuNPs synthesis ${ }^{7,8}$. However, in spite of the popularity and extensive usage of citrate based methods for synthesis of AuNPs ${ }^{9,10}$, there has been limited introspection in literature into the probable interaction between citrate and gold ions along with the structural details of citrate adsorption.

The mechanism of adsorption of citrate ions on gold surface reported so far discuss this issue more from qualitative perspective than quantitative ${ }^{11,12}$ In an earlier such report, the structural details of adsorption of citrate ion have been discussed exhibiting the formation of three carboxylate groups coordinated as $\eta-2$ bonded carboxylate adsorbate with characteristic infrared absorbance at around $1390 \mathrm{~cm}^{-1}$ coordinated to the Au (111) surface in an acidic electrolyte ${ }^{13}$. Similarly, subtractively normalized interfacial Fourier transform infrared spectroscopy has been used for quantification of surface coverage of AuNPs $\left(\sim 3 \times 10^{-10} \mathrm{~mol} / \mathrm{cm}^{2}\right)$. This is based on the fact that all three carboxylic groups of citric acid undergo deprotonation ${ }^{14}$. The authors have also postulated that the carboxylate groups take a tilted conformation on AuNP surface. Further, the thermodynamic description of adsorption of citric acid and dihydrogen citrate on $\mathrm{Au}$ (111) surface has been studied using electrochemical methods such as chronocoulometry and cyclic voltammetry comparing the adsorption of citrate at different $\mathrm{pH}^{15}$. The general observation was that the surface coverage increased three-fold as $\mathrm{pH}$ was raised from 1 to 3 .In a recent study, the effect of thedecrease in $\mathrm{pH}$ from 5.3 to 4.7 resulted in the reduction of the AuNP concentrationby $46 \%{ }^{16}$.

Atomistic molecular dynamics simulations (MD) have been used to understand different binding modes of citrate ion onto AuNP surface where it was concluded that the orientation of citrate is such that carboxylate groups point towards water (solvent) molecules and are stabilized by complex interplay between citrate-gold and citrate-citrate interactions ${ }^{17}$. It is pertinent to mention here that these simulation studies have been based on the assumption that there were only two binding possibilities of citrate ion onto AuNP surface, one through central carboxylate group of citrate alone and other with the terminal carboxylate groups. Similarly, MD based on a

${ }^{1}$ Department of Chemistry and Centre for Advanced Studies in Chemistry, Panjab University, Chandigarh, 160014, India. ${ }^{2}$ Department of Applied Sciences, University Institute of Engineering and Technology, Panjab University, Sector 25, Chandigarh, 160014, India. ${ }^{3}$ D.V.S. Jain is deceased. ${ }^{\bowtie}$ e-mail: rohitksg@pu.ac.in 


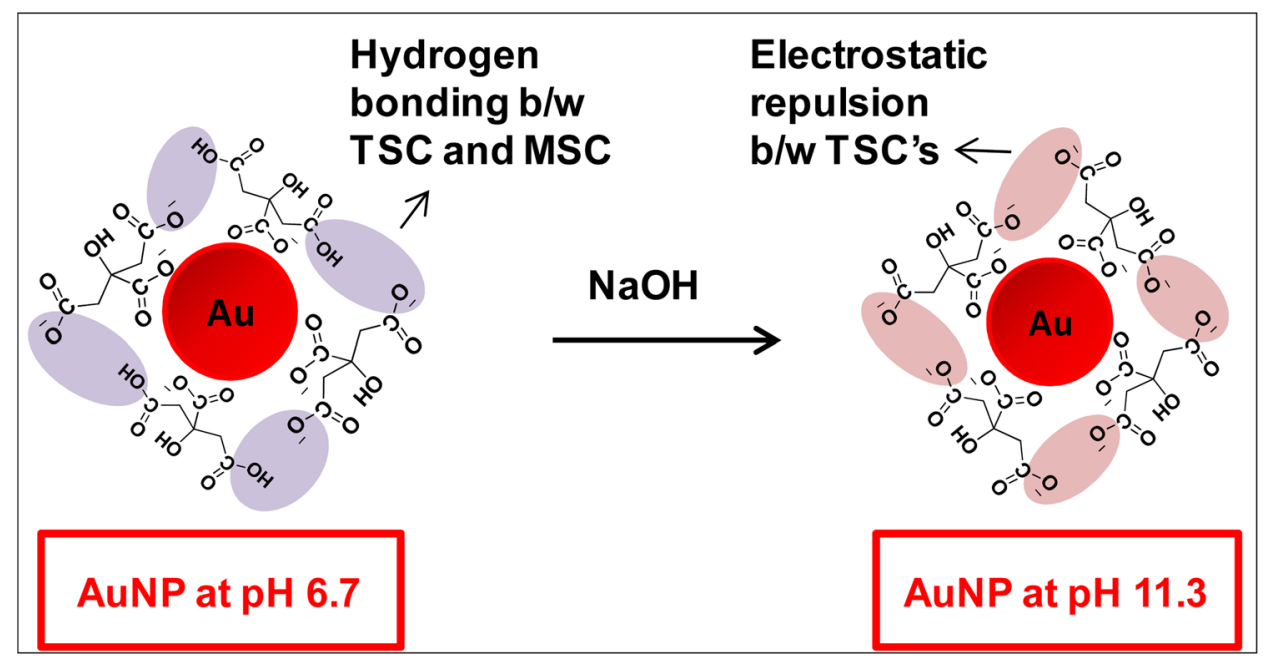

Figure 1. Schematic reaction illustrating different binding of citrate ions on the surface of AuNPs (at pH 6.7 and $\mathrm{pH} 11.3$ ).

reactive force field has been used to investigate the absorption modes of citrate on AuNPs ${ }^{18}$. It was revealed that $50 \%$ of the adsorbates binds with AuNPs through one of the terminal carboxyl group while other $50 \%$ through both the central and a terminus carboxyl group. In another report using MDS, it has been reported that the dihydrogen citrate is the predominant configuration of citratepresent over AuNP surface ${ }^{19}$.

Recently, binding modes of various carboxylate-containing systems such as citrate, acetate, succinate and glutarate with AuNPs has been examined using ${ }^{13} \mathrm{C}$ and ${ }^{23} \mathrm{Na}$ solid-state $\mathrm{NMR}^{20}$. It has been reported that these systems possessed three different modes to AuNPs surface; out of which monodentate mode is most favoured. Further, the conformation of citrate anions on AuNPs was investigated using IR and X-ray photoelectron spectroscopy which basically discussed the adsorption of citrate anions through the central carboxylate group ${ }^{21}$. This was supported by structure-based model of citrate adsorption on $\mathrm{Au}(111)$ in which only syn conformers i.e. mono-sodium citrate (MSC) was adsorbed in bridge sites which interacted with each other and dangling citrate. The alkaline conditions convert the monodentate citrate ion into tri-sodium citrate (TSC) which undergoes tetradentatecoordination upon binding of the hydroxyl and carboxyl groups to the surface. Based on these findings, it was proposed that the formation of citrate layer is favoured on $\mathrm{Au}(111)$ but deterred over $\mathrm{Au}(110) \mathrm{and} \mathrm{Au}(100)$. However, no experimental evidence was provided and this as well as earlier discussed reports did not focus on quantification of citrate ions over nanoparticle surface.

Keeping the above considerations in mind, the present report is a major step forward in understanding the actual mechanistic behaviour of citrate ions on Au surface. Herein, the concentration of citrate ions present on AuNPs have been tried to be quantified using thermogravimetric analysis (TGA) carried out on the dried AuNPs synthesized by Turkevich method (Fig. 1). The behaviour of citrate ions on nanoparticle surface was further assessed by varying reaction parameters such as concentration of TSC and pH of the colloidal solution. The results presented here are quite significant as we have found that surface concentration increases as the $\mathrm{pH}$ is raised contrary to most of the earlier studies ${ }^{21}$. These findings also underline the importance of using TGA as a new tool for quantification of citrate anions onto metallic nanoparticle surfaces. It is pertinent to mention here that to the best of our knowledge, this is the first report where the mechanism of AuNPs synthesis using Turkevich has been tried to be understood based on actual quantification of citrate ions.

Initially, the concentration of TSC was varied from $34 \mathrm{mM}$ to $68 \mathrm{mM}$ to synthesize AuNPs using Turkevich method. It was observed that the increase in the concentration of the TSC led to a blue shift in the absorption maxima which may be attributed to the size variation of AuNPs (Fig. S1). Also, it is known that the ratio of gold ion to TSC concentration have a significant effect on the morphology of the citrate-stabilized AuNPs ${ }^{22}$. Further to check it, TEM analysis was performed which showed the spherical shape of AuNPs with monodispersive nature and the average size of the AuNPs was found to be of the order of $18( \pm 1) \mathrm{nm}$ (termed as Au-18) and $15( \pm 1) \mathrm{nm}$ (termed as Au-15) (calculated from the histograms obtained with the help of ImageJ software) corresponding to $34 \mathrm{mM}$ and $68 \mathrm{mM}$ citrate concentrations, respectively (Fig. S2A-D).

As per experimental evidences, it has reported that there exist mainly two types of citrate conformers on the surface of AuNPs during Turkevich synthesis ${ }^{20,21}$. Under neutral $\mathrm{pH}$ range, the citrate ions are present mostly in the form of dihydrogen citrate (or MSC) whereas they get converted to TSC in alkaline condition. Keeping this into consideration, the decomposition behaviour of MSC and Au-18 (at pH 6.7) was compared using TGA (Fig. 2A,B). The MSC decomposed completely when heated up to $1000^{\circ} \mathrm{C}$ with final mass becoming zero residual mass (Fig. 2A) ${ }^{23}$. On similar lines, in Batch I when Au-18 at pH 6.7 (5.5530 mg) were thermo-gravimetrically analyzed up to same temperature limit (Fig. 2B), the entire MSC decomposed leading to pure gold in form of nanoparticles as left over final product as $5.3342 \mathrm{mg}(\mathrm{w})$ (Fig. 2C). The residual mass of Au and the size of AuNPs as measured by electron microscopy were used to calculate number of AuNPs. In order to find out the actual concentration of citrate ions on the surface of AuNPs, following mathematical equations (eqs.) (1-5) have been used. 

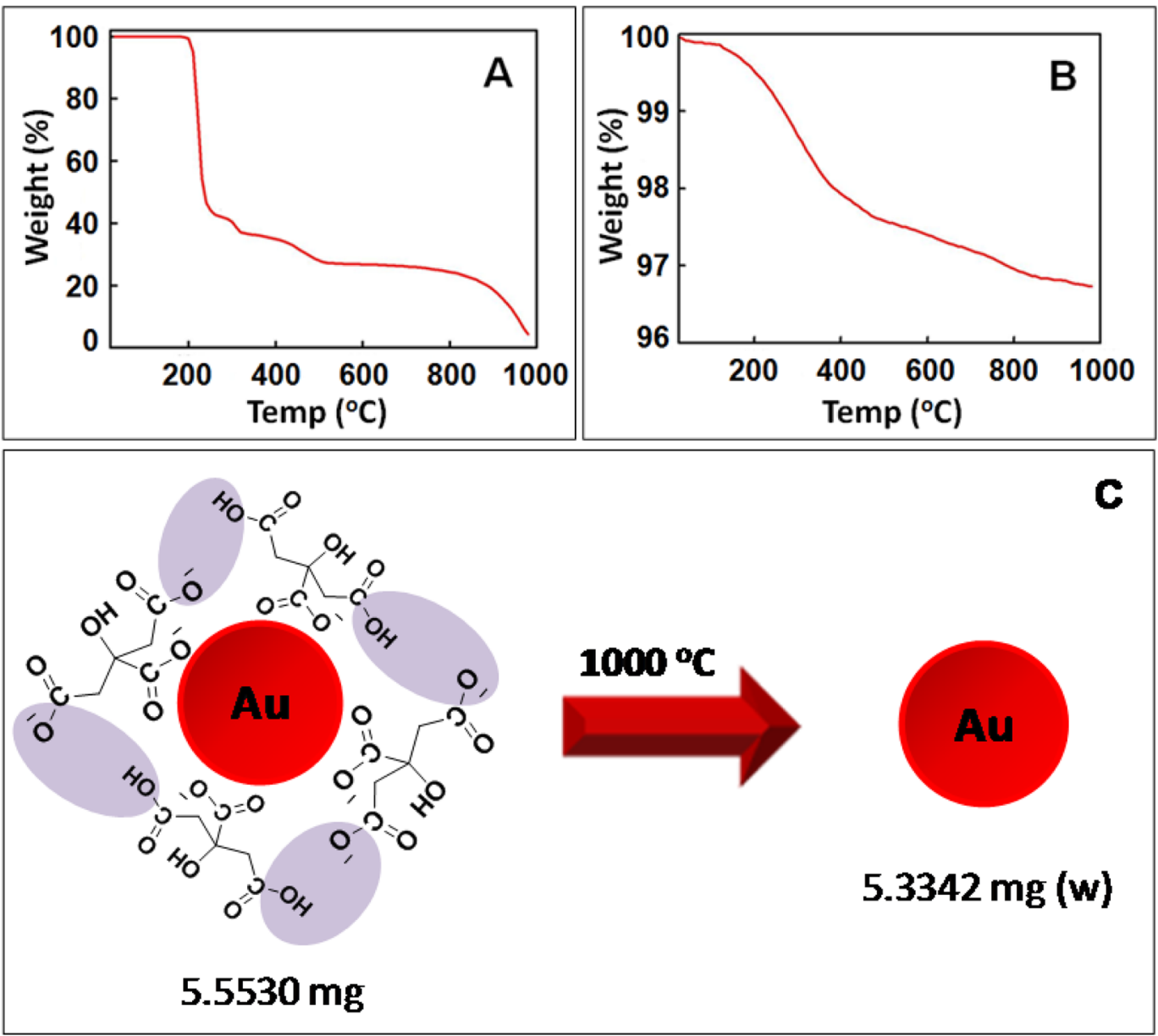

Figure 2. TG curve (Batch I) (A) MSC, (B) Au-18 at pH 6.7; and (C) Schematic reaction showing decomposition of Au-18 (at pH 6.7).

$$
\begin{gathered}
\mathbf{V}_{\mathrm{Au}(\text { left })}=\mathrm{w} / \rho_{\mathrm{Au}} \\
\mathbf{N}_{\text {AuNPs }}=\mathrm{V}_{\mathrm{Au}(\text { left })} / \mathrm{V}_{\mathrm{Au}} \\
\mathbf{N}_{\mathbf{t}}=\mathrm{m}_{\mathrm{m}} \times \mathrm{N}_{\mathrm{o}} \\
\mathbf{N}_{\mathbf{t} / \mathrm{AuNP}}=\mathrm{N}_{\mathrm{t}} / \mathrm{N}_{\mathrm{AuNPs}} \\
\mathbf{C}_{\mathbf{t}}=\mathrm{N}_{\mathrm{t} / \mathrm{AuNP}} / \mathrm{A}_{\mathrm{Au}} \times \mathrm{N}_{\mathrm{o}}
\end{gathered}
$$

In Eq. 1, the amount of Au left $(w)$ after decomposition is divided by density of gold $\left(\rho_{\mathrm{Au}}\right)$ to give the volume of $\mathrm{Au}$ left $\left(\mathrm{V}_{\mathrm{Au}(\mathrm{left})}\right)$; from which number of AuNPs $\left(\mathrm{N}_{\mathrm{AuNPs}}\right)$ can be deduce in Eq. 2 using volume of $\mathrm{Au}\left(\mathrm{V}_{\mathrm{Au}}\right)$. After that, by multiplying the number of moles of citrate ions lost during decomposition $\left(\mathrm{m}_{\mathrm{m}}\right)$ with Avogadro's number $\left(\mathrm{N}_{\mathrm{o}}\right)$ provides the total number of citrate molecules $\left(\mathrm{N}_{\mathrm{t}}\right)$ attached to AuNPs (Eq. 3). Further $\mathrm{N}_{\mathrm{t}}$ and $\mathrm{N}_{\text {AuNPs }}$ are used to figure out the number of citrate molecules per $A u N P\left(N_{t / A u N P}\right)$ (Eq. 4). Finally, Eq. 5 will be used to find out the citrate ion concentration $\left(C_{t}\right)$ covering AuNP surface using $N_{t / A u N B}$ surface area of $A u\left(A_{A u}\right)$ and $N_{o}$.

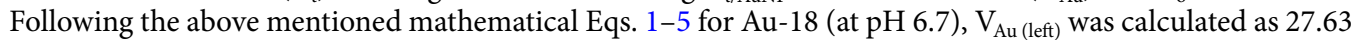
$\times 10^{-11} \mathrm{~m}^{3}$ (Eq. 1); from which $\mathrm{N}_{\text {AuNPs }}$ was found to be $9.05 \times 10^{13}$ using $\mathrm{V}_{\mathrm{Au}}\left(4 \pi \mathrm{r}^{3} / 3=3.052 \times 10^{-24} \mathrm{~m}^{3}\right)($ Eq. 2$)$. After that, $\mathrm{N}_{\mathrm{t}}$ was deduced to be $0.504 \times 10^{18}$ (Eq. 3) which further helped to calculate $\mathrm{N}_{\mathrm{t} / \mathrm{AuNP}}$ as $5.569 \times 10^{3}$ (Eq. 4). The $\mathrm{A}_{\mathrm{Au}}\left(4 \pi \mathrm{r}^{2}=10.17 \times 10^{-12} \mathrm{~cm}^{2}\right)$ was used to find out $\mathrm{C}_{\mathrm{t}}$ which is coming out to be $9.09 \times 10^{-10} \mathrm{~mol} /$ $\mathrm{cm}^{2}$ (Eq. 5).

As discussed earlier, under alkaline condition MSC ions convert into the TSC ions on AuNP surface. So, the varying $\mathrm{pH}$ has been known to be a crucial factor ${ }^{16}$ affecting the concentration of citrate ions on AuNP surface which may also give a definitive evidence for mechanism of synthesis of AuNPs via Turkevich method. Thus, for understanding the quantification of citrate ions in alkaline condition, the $\mathrm{pH}$ of the purified Au-18 after 

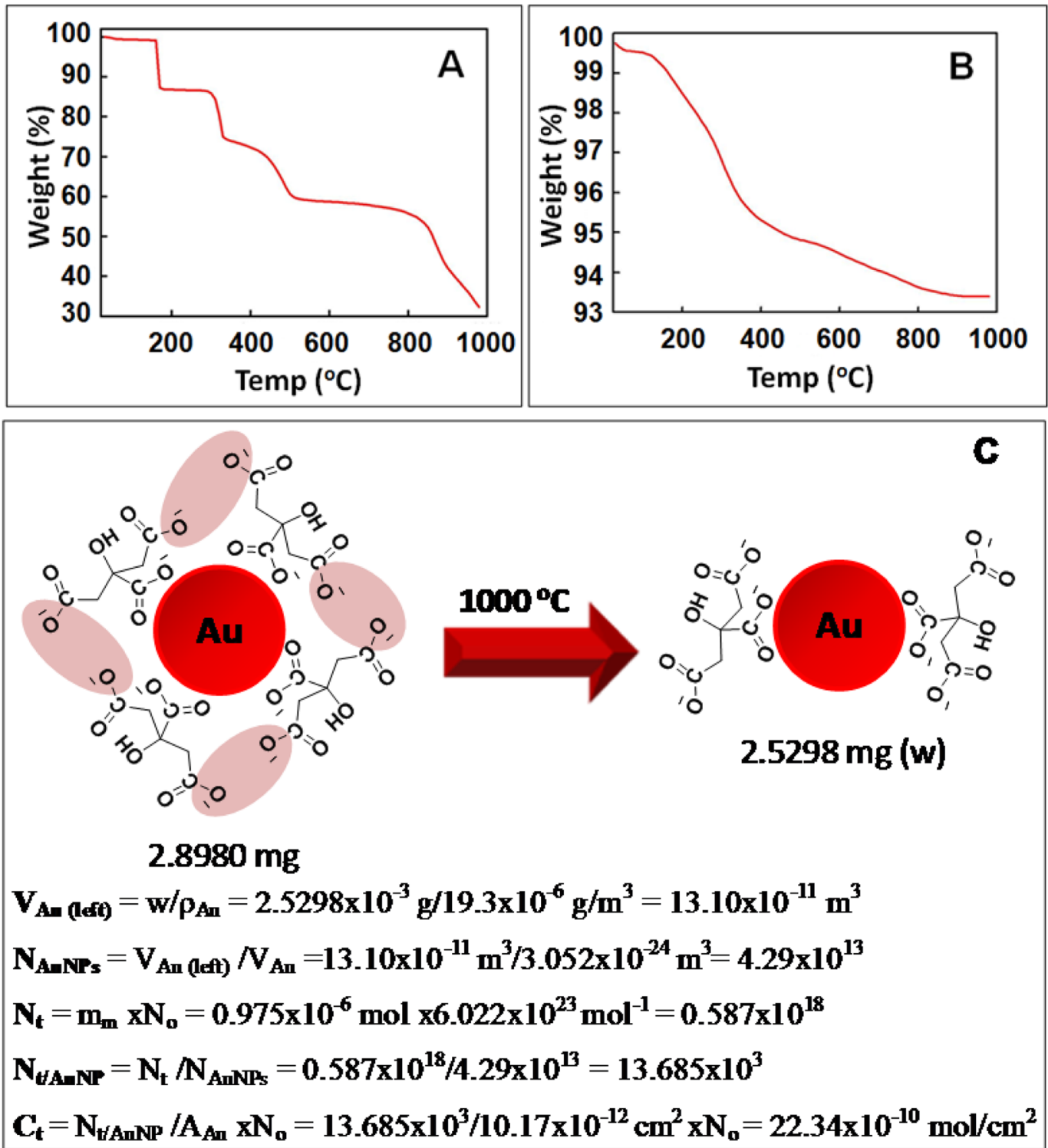

Figure 3. TG curve (Batch I) (A) MSC, (B) Au-18 at pH 11.3; and (C) Schematic reaction showing decomposition of Au-18 (at pH 11.3).

re-dispersion in water was adjusted to 11.3 using $0.1 \mathrm{M}$ sodium hydroxide in order to reduce citrate layers formed by hydrogen bonding between adsorbed citrate and free citrate ${ }^{21}$.

The decomposition behaviour of $\mathrm{Au}-18$ (at pH 11.3) and TSC was compared using TGA (Fig. 3A,B). However, in contrast to the decomposition behaviour of MSC which completely decomposed, the TSC does not decompose entirely at $1000^{\circ} \mathrm{C}$ as $70 \%$ mass decomposition was observed (Fig. 3A) ${ }^{23}$. On similar lines, when Au-18 at pH 11.3 $(2.8980 \mathrm{mg})$ were heated up to same temperature, $93 \%$ of mass remained $(2.5298 \mathrm{mg})$ which presumably contain $30 \%$ residual mass of TSC (Fig. 3B). This residual mass of TSC was accounted for calculation of citrate ion per AuNP and concentration of citrate ions per unit area at $\mathrm{pH} 11.3$ as per previously discussed Eqs. 1-5. From the calculations, $\mathrm{N}_{\mathrm{t} / \mathrm{AuNP}}$ and $\mathrm{C}_{\mathrm{t}}$ was calculated as $13.685 \times 10^{3}$ and $22.34 \times 10^{-10} \mathrm{~mol} / \mathrm{cm}^{2}$. This experiment was performed in triplicates (Batch II and Batch III) for Au-18 (Figs. S3 and S4) and the average $\mathrm{N}_{\mathrm{t} / \text { AuNP }}$ was determined as $5.5 \pm 0.4$ at $\mathrm{pH} 6.7$ and $13.0 \pm 2.2$ at $\mathrm{pH} 11.3$ respectively, further the average $\mathrm{C}_{\mathrm{t}}$ was deduced as $9.0 \pm 0.6 \mathrm{~mol} /$ $\mathrm{cm}^{2}$ at $\mathrm{pH} 6.7$ and $21.2 \pm 3.6 \mathrm{~mol} / \mathrm{cm}^{2}$ at $\mathrm{pH} 11.3$. The complete calculations deduced from all three measurements have been summarized in Table S1.

Thus, it can be clearly seen that the number of citrate ion found at $\mathrm{pH} 11.3\left(13.0 \pm 2.2 \times 10^{3}\right)$ were much higher than that at pH $6.7\left(5.5 \pm 0.4 \times 10^{3}\right)$. Interestingly, contrary to general belief and previous report ${ }^{21}$, the surface density of TSC on AuNP surface was observed to be much higher under alkaline conditions. Although the TSC ions are unable to form hydrogen bonds as MSC ions which is probably the reason for earlier reporting, the explanation for increased concentration TSC ions under basic condition is the alternative stronger ionic 

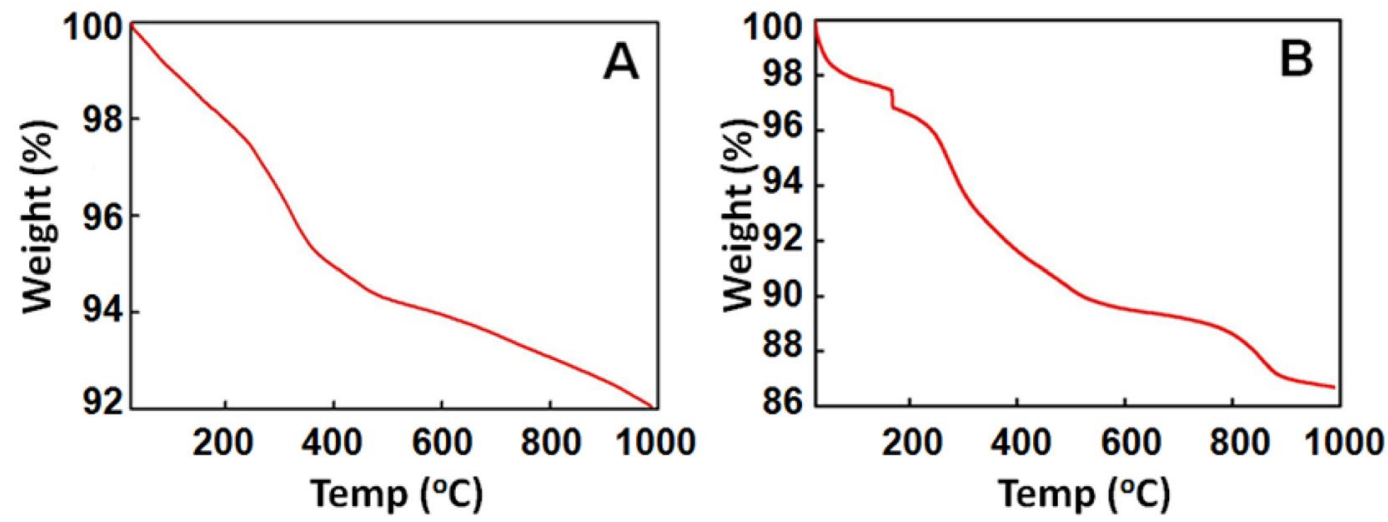

Figure 4. TG curve (Batch I) (A) Au-15 at pH 6.7 and (B) Au-15 at pH 11.3.

interactions between sodium salts of carboxylate anions. In other words, the enhancement of negatively charged carboxylate anions of citrate at higher $\mathrm{pH}$ results in the increase of citrate ions under alkaline conditions.

To verify the applicability of present method for assessment of the quantification of citrate ions for different sizes of AuNPs, Au-15 nanoparticles were analyzed in similar manner as described earlier at pH 6.7 and 11.3 using TGA (Fig. 4A,B).

Analogous to the calculation template discussed for $\mathrm{Au}-18$ nanoparticles, $\mathrm{N}_{\mathrm{t} / \mathrm{AuNP}}$ for $\mathrm{Au}-15$ was calculated to be $7.176 \times 10^{3}$ at $\mathrm{pH} 6.7$ (Fig. S5) and $18.276 \times 10^{3}$ at $\mathrm{pH} 11.3$ (Fig. S6). Correspondingly, $\mathrm{C}_{\mathrm{t}}$ was found to be $16.87 \times 10^{-10} \mathrm{~mol} / \mathrm{cm}^{2}$ at pH 6.7 (Fig. S5) and $42.98 \times 10^{-10} \mathrm{~mol} / \mathrm{cm}^{2}$ at pH 11.3 (Fig. S6) respectively. This experiment was also performed in triplicates (Batch II and Batch III) for Au-15 (Figs. S7 and S8) and the average $\mathrm{N}_{\mathrm{t} / \mathrm{AuNP}}$ was determined as $7.3 \pm 1.0$ at $\mathrm{pH} 6.7$ and $16.6 \pm 1.6$ at $\mathrm{pH} 11.3$ respectively, further the average $\mathrm{C}_{\mathrm{t}}$ was deduced as $17.2 \pm 2.5 \mathrm{~mol} / \mathrm{cm}^{2}$ at $\mathrm{pH} 6.7$ and $39.0 \pm 3.7 \mathrm{~mol} / \mathrm{cm}^{2}$ at $\mathrm{pH} 11.3$. The complete calculations deduced from all three measurements have been summarized in Table S2.

The data for Au-15 correspond to that of Au-18 in a way that $\mathrm{N}_{\mathrm{t} / \mathrm{AuNP}}$ along with $\mathrm{C}_{\mathrm{t}}$ are augmenting as $\mathrm{pH}$ is increased (contrary to earlier hypothesis) ${ }^{21}$. It leads to another interesting observation that change in concentration of TSC does not have significant effect on the quantification trend of citrate ion on AuNPs at different reaction conditions. Importantly, these figures validate the TGA method for quantitative analysis of citrate ions on the surface of gold as well as give important inputs about the behaviour of citrate ions at neutral and basic $\mathrm{pH}$.

In summary, TGA has been demonstrated as a new tool for the quantitative determination of citrate anions present on the AuNP surface. In earlier reports, mechanism of AuNPs synthesis was discussed only from the point of qualitative aspect but not quantitative. Thus, the determination of actual number of citrate ions present on the surface of AuNPs is essential as well as crucial for real understanding of the structure of AuNPs synthesized by Turkevich method. Also the understanding of the quantification on the surface of nanomaterials is crucial for mechanistic study of their synthetic pathway. For this purpose, two different sized AuNPs were synthesized by varying the concentration of TSC and were subjected to TGA analysis at different reaction conditions by varying the $\mathrm{pH}$ of the colloidal solutions. Based on the decomposition behaviour of thermogravimetric curve, it was observed that the number of citrate ions present on the surface of nanoparticle is highly $\mathrm{pH}$ dependent and was relatively much more in alkaline conditions which contradict the earlier hypothesis (Fig. 5). This was explained on the basis of the stronger ionic interactions between sodium salts of carboxylate anions which were observed under basic conditions. It is pertinent to mention here that this is the first report related where quantification of citrate ions present on AuNPs was done. Also, the change in the concentration of TSC does not make any significant effect on the trend of quantification of citrate ions. These experiments have been extensively characterized and validated to fully understand the adsorption of citrate ions.

The out comings of this work set up a platform to study the surface of nanoparticle and provide new methodology to quantify the number of ligand/biomolecule present on the nanoparticle surface which was not possible earlier. It resolves the level of understanding of the mechanism of formation of AuNPs. These findings also underline the importance of using TGA as a new tool for quantification of citrate anions on gold nanoparticle surface. It provides new heights of understanding to very popular Turkevich method. This detailed study will provide new insight in the up growing field of nanotechnology. Further research to apply this methodology on other materials is underway.

\section{Methods}

Reagents. Tetrachloroauric acid $\left(\mathrm{HAuCl}_{4}\right)$, tri-sodium citrate (TSC), mono-sodium citrate (MSC) and sodium hydroxide were obtained from Sigma, India and were used as received. Ultrapure water used in the synthesis has a resistivity of $18 \mathrm{M} \Omega$. All the glassware and magnetic beads used in the experiment were cleaned using aqua regia and rinsed with ultrapure water.

Synthesis and characterization of gold nanoparticles. Synthesis of AuNPs. To the boiling solution of $0.25 \mathrm{mM}$, tetrachloroauric acid; varying concentrations $(34 \mathrm{mM}, 68 \mathrm{mM})$ of an aqueous solution of TSC was added. The heating was continued until a deep ruby red color appeared. The particles were purified using repeated 


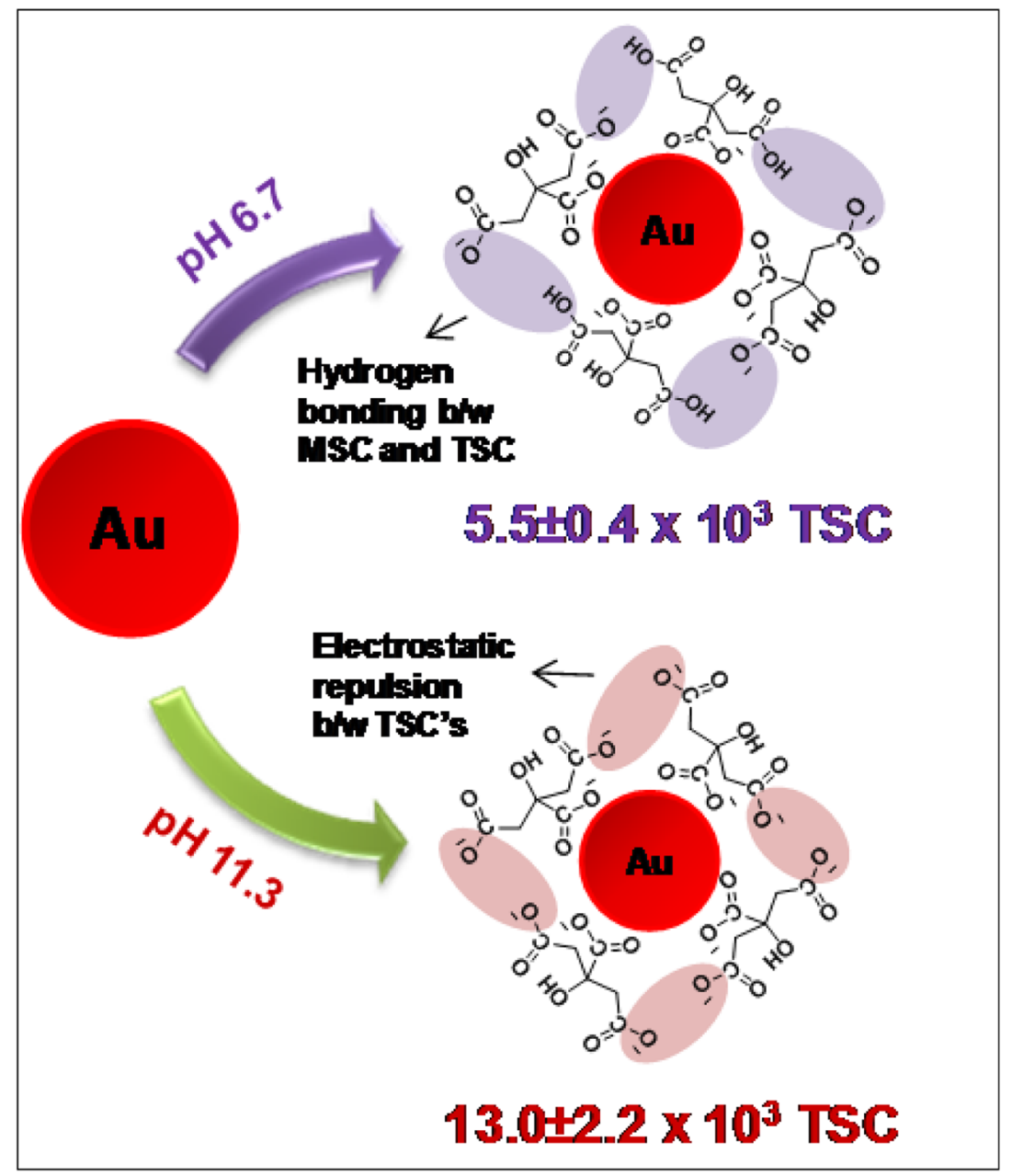

Figure 5. Graphical representation illustrating $\mathrm{pH}$ dependent quantification of citrate ions on AuNP surface.

cycles of centrifugation at $9000 \mathrm{rpm}$ and re-dispersing in ultrapure water. The resulting particles were characterized using UV-visible (UV-vis) spectroscopy and transmission electron microscopy (TEM). The process was scaled up by taking a much larger volume $(500 \mathrm{ml}$ or more) of tetrachloroauric solution so that more than $4 \mathrm{mg}$ of dry AuNPs could be isolated. The particles were prepared at two $\mathrm{pH}$ values ( $\mathrm{pH} 6.7$ \& $\mathrm{pH} 11.3$ ) and their pellet was lypholized for thermogravimetric analysis (TGA).

Characterization of AuNPs. UV-visible spectroscopy. UV-visible spectrophotometer (Jasco, V-530) was used to confirm the formation of AuNPs by checking their surface plasmon resonance.

Transmission electron microscopy (TEM) analysis. TEM technique was used to determine the shape and size of the AuNPs. Sample was prepared on carbon coated grid and dried before analysis under TEM (H-7500, Hitachi) operating at an acceleration voltage of $40 \mathrm{kv}$ to $120 \mathrm{kv}$ equipped with CCD camera with a resolution of $0.36 \mathrm{~nm}$.

Thermogravimetric analysis (TGA). TGA-SDT Q 600, TA was used in the temperature range of $25-1000^{\circ} \mathrm{C}$ heating at the rate of $20^{\circ}$ per minute. The solid samples of MSC and TSC (as purchased) and AuNPs (after lyophilisation) were analyzed using TGA.

Received: 19 June 2019; Accepted: 11 February 2020;

Published online: 19 May 2020

\section{References}

1. Yeh, Y.-C., Creran, B. \& Rotello, V. M. Gold nanoparticles: preparation, properties, and applications in bionanotechnology. Nanoscale 4, 1871-1880 (2012).

2. Boisselier, E. \& Astruc, D. Gold nanoparticles in nanomedicine: preparations, imaging, diagnostics, therapies and toxicity. Chem. Soc. Rev. 38, 1759-1782 (2009).

3. Dykman, L. \& Khlebtsov, N. Gold nanoparticles in biomedical applications: recent advances and perspectives. Chem. Soc. Rev. 41, 2256-2282 (2012).

4. Saha, K., Agasti, S. S., Kim, C., Li, X. \& Rotello, V. M. Gold Nanoparticles in Chemical and Biological Sensing. Chem. Rev. 112, 2739-2779 (2012). 
5. Herizchi, R., Abbasi, E., Milani, M. \& Akbarzadeh, A. Current methods for synthesis of gold nanoparticles. Artif. Cells Nanomed. Biotechnol 2, 596-602 (2014).

6. Turkevich, J., Stevenson, P. C. \& Hillier, J. A Study of the nucleation and growth processes in the synthesis of colloidal gold. Discuss. Faraday Soc 11, 55-75 (1951).

7. Glusker, J. P. Acc. Chem. Res. 13, 345-352 (1980).

8. Rani, M. et al. Understanding the mechanism of replacement of citrate from the surface of gold nanoparticles by amino acids: A theoretical and experimental investigation and their biological application. RSC Adv. 6, 17373-17383 (2016).

9. Kimling, J. et al. Turkevich Method for Gold Nanoparticle Synthesis Revisited. J. Phys. Chem. B 110, 15700-15707 (2006).

10. Wuithschick, M. et al. Turkevich in New Robes: Key Questions Answered for the Most Common Gold Nanoparticle Synthesis. ACS Nano 9, 7052-7071 (2015).

11. Ojea-Jimenez, I., Bastus, N. G. \& Puntes, V. Influence of the sequence of the reagents addition in the citrate-mediated synthesis of gold nanoparticles. J. Phys. Chem. C 115, 15752-15757 (2011).

12. Schulz, F. et al. Little Adjustments Significantly Improve the Turkevich Synthesis of Gold Nanoparticles. Langmuir 30, 10779-10784 (2014).

13. Floate, S. et al. An in-situ infrared spectroscopic study of the adsorption of citrate on Au(111) electrodes. J. Electroanal. Chem. 542, 67-74 (2003).

14. Nichols, R. J., Burgess, I., Young, K. L., Zamlynny, V. \& Lipkowski, J. A quantitative evaluation of the adsorption of citrate on Au(111) using SNIFTIRS. J. Electroanal. Chem. 563, 33-39 (2004).

15. Kunze, J., Burgess, I., Nichols, R., Buess-Herman, C. \& Lipkowski, J. Electrochemical evaluation of citrate adsorption on Au(111) and the stability of citrate-reduced gold colloids. J. Electroanal. Chem. 599, 147-159 (2007).

16. Contreras-Trigo, B. et al. Slight $\mathrm{pH}$ fluctuations in the gold nanoparticle synthesis process influence the performance of the citrate reduction method. Sensors 18, 2246 (2018).

17. Wright, L. B., Rodger, P. M. \& Walsh, T. R. Structure and properties of citrate overlayers adsorbed at the aqueous Au(111) interface. Langmuir 30, 15171-15180 (2014).

18. Monti, S., Barcaro, G., Sementa, L., Carravetta, V. \& Agren, H. Characterization of the adsorption dynamics of trisodium citrate on gold in water solution. RSC Adv. 7, 49655-49663 (2017).

19. Chong, G. et al. Density, Structure, and Stability of Citrate ${ }^{3-a n d ~} \mathrm{H}_{2}$ citrate-on Bare and Coated Gold Nanoparticles. J. Phys. Chem. C 122, 28393-28404 (2018).

20. Al-Johani, H. et al. The structure and binding mode of citrate in the stabilization of gold nanoparticles. Nat. Chem. 9, 890-895 (2017).

21. Park, J.-W. \& Shumaker-Parry, J. S. Structural Study of Citrate Layers on Gold Nanoparticles: Role of Intermolecular Interactions in Stabilizing Nanoparticles. J. Am. Chem. Soc. 136, 1907-1921 (2014).

22. Shi, L., Buhler, E., Boue, F. \& Carn, F. How does the Size of Gold Nanoparticles Depend on Citrate to Gold Ratio in Turkevich Synthesis? Final Answer to a Debated Question. J. Colloid Interface Sci. 492, 191-198 (2016).

23. Gao, J., Wang, Y. \& Hao, H. Investigations on dehydration processes of trisodium citrate hydrates. Front. Chem. Sci. Eng 6, 276-281 (2012).

\section{Acknowledgements}

This work is dedicated to the memory of Late Prof. D. V. S. Jain, one of the authors of this manuscript, who left for heavenly abode in October 2019. Financial support from Science Engineering \& Research Board (SERB), India grant no. EMR/2016/007967 and DST-PURSE II grant and University Grants Commission (UGC) Fellowship Program to M. B. is gratefully acknowledged.

\section{Author contributions}

M.B. performed the experiments; D.V.S.J. developed overall scheme and methodology for calculations; R.K.S. developed the methods and wrote the main manuscript text; R.K.S. and N.W. edited and supervised the work.

\section{Competing interests}

The authors declare no competing interests.

\section{Additional information}

Supplementary information is available for this paper at https://doi.org/10.1038/s41598-020-65013-0.

Correspondence and requests for materials should be addressed to R.K.S.

Reprints and permissions information is available at www.nature.com/reprints.

Publisher's note Springer Nature remains neutral with regard to jurisdictional claims in published maps and institutional affiliations.

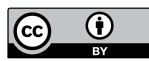

Open Access This article is licensed under a Creative Commons Attribution 4.0 International License, which permits use, sharing, adaptation, distribution and reproduction in any medium or format, as long as you give appropriate credit to the original author(s) and the source, provide a link to the Creative Commons license, and indicate if changes were made. The images or other third party material in this article are included in the article's Creative Commons license, unless indicated otherwise in a credit line to the material. If material is not included in the article's Creative Commons license and your intended use is not permitted by statutory regulation or exceeds the permitted use, you will need to obtain permission directly from the copyright holder. To view a copy of this license, visit http://creativecommons.org/licenses/by/4.0/.

(C) The Author(s) 2020 